\title{
Increasing Role of Cloud Computing In Business, Challenges and Decline In Challenges with Cloud Maturity
}

\author{
Musaddiq Azeem ${ }^{1}$, Ahsan Raza Sattar ${ }^{2}$, Muhammad Yasir ${ }^{3}$, Bilal Safdar ${ }^{4}$ \\ ${ }^{1}$ Department of Computer Science, University of Agriculture Faisalabad, musaddiqazeem@ gmail.com \\ ${ }^{2}$ Department of Computer Science, University of Agriculture Faisalabad, ahsan_raza @ uaf.edu.pk \\ ${ }^{3}$ Department of Computer Science, University of Agriculture Faisalabad, yasirfsd1@ gmail.com \\ ${ }^{4}$ Department of Computer Science, University of Agriculture Faisalabad, bilalsafdar2558@ gmail.com
}

\begin{abstract}
The quick improvement of handling and storage technologies and success of the Internet, computing devices are now less expensive, more accessible. This innovative method has enabled the new business model that is cloud computing, in this model, resources are provided as common service that client takes on lease on the Internet. The corporations are showing more interest and participation in cloud computing and they started to move their businesses on cloud computing. In past few years, cloud computing technology set up as an emerging research point. Numerous analysts, in any case, concentrate only on technological aspects of cloud technology, thereby ignoring the business openings and possibilities that can be offered by cloud technology. The focus of this paper lies on the increasing role of cloud computing in business and also how cloud computing influencing business positively. We will also discuss about challenges for cloud computing to completely penetrate in business and how these challenges are declining with time and also with cloud maturity. As the enterprises matured in cloud environment the overall challenges reduced very quickly.
\end{abstract}

Key words: Cloud computing, Business opportunities, Cloud Maturity, Increasing role, Business model, Decline in Challenges

\section{INTRODUCTION:}

Cloud technology is abroad purpose technology based on internet in which information is kept on server machines and delivered as a service to the clients on their demand. Implementing the endogenic market structural approach to economics, we examine the financial effect of the ongoing introduction of cloud computing and we emphasize its role in fostering business creation and competition [1].

Most of the researchers, only concentrate entirely on technological features of cloud technology, by ignoring its business openings and capabilities that can be offered by cloud technology. By enabling the cloud technology, lot of new players of market and different business networks arises and ending the out dated methods, that providing these services [2].We have to scrutinize all the +ve and -ve features from these elements: assimilation with current IT structure and current software system, prices, what is profit on this investment, outputs, and safety. We should compare all above mentioned thing with the size and requirements, to analyze what type of requirements company has related to implementation of cloud technology [3]. Cloud computing technology attracting the corporations and small businesses as well because it eliminate many required things that they need to plan before implementation and give them possibility to start with minimum resources. It also allow them to increase their services and resources as their demand increases [4]. Cloud Computing is not essentially a new model. It based on previous knowledge and methods for example Utilization of Computers, Software as a Service, spread computing, and central data centers [5].

\section{WHAT IS CLOUD COMPUTING?}

"Cloud Computing is a setup where we provide computing resource as service on any network, usually the internet."

Rather than deploying hardware and software personally or locally, cloud computing depends on sharing a pool of resources (Physical or virtual). As a user you are able to use pool of resources without any effort to generate these resources.

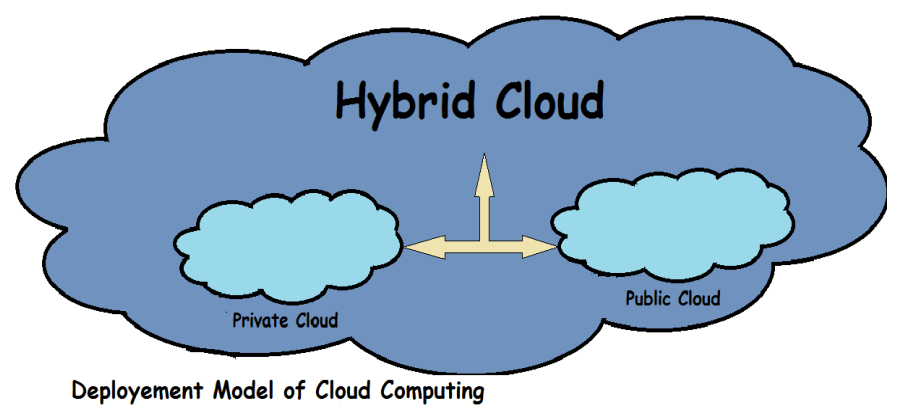




\subsection{Models of cloud computing}

There are following model types of cloud computing that universally recognized.

Figure 1 Deployment model of cloud computing

Deployment models

Service models

\subsubsection{Deployment models:}

From deployment point of view cloud computing has three following three types. Asshown in figure 1.

\subsubsection{Private Cloud:}

In Private clouds pool services are stored and managed on a secured or private network which can be accessed only users who has rights to do so. Resources can be virtual or physical.

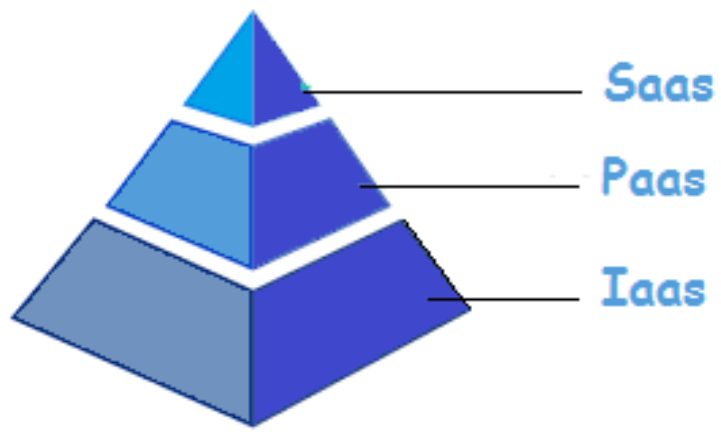

Figure 2Service model of cloud computing

Private cloud has great level of security and control over network that solve vulnerability issue. On the other hand it has some issues related to cost. We have to sacrifice cost benefits to some extent.

A private cloud might be constructed by association or might be outside suppliers. Private cloud provides the top level control on performance, consistency and safety [6].

\subsubsection{Public Cloud:}

In public cloud, service provider make service (storages, applications and all the virtual machines) available to general user over public network (internet). Public clouds have great cost benefits but on the other hand it has many security issues than private cloud because of its availability on public network. Public clouds has deficiency in control on records, net and safety settings that reduced their efficiency in many businesses where these things are very important [6].

\subsubsection{Hybrid Clouds:}

Hybrid cloud has characteristics from both public and private cloud models. As name of hybrid cloud states that it is the combination of both deployment models. The major advantage of hybrid cloud is; an enterprise can use public cloud for lesssensitive operations and for more sensitive or critical operations it has option of private cloud.

Some of the down sides of hybrid, scheming a hybrid cloud needs wisely defining the best splitting among both private and public cloud modules [6].

\subsubsection{Service models:}

Broadly Speaking, from service point of view cloud computing has following three basic models.

\subsubsection{Infrastructure as a Service (IaaS):}

When we talk about service models, IaaS is the basic model of cloud computing. IaaS refers to provide virtual computing resources across the internet. It is basically deal with hardware. "Main idea behind IaaS model is to provide virtual environment, in which user have virtual desktop environment and use many assets for example net, storing, servers that virtualized and routers etc. provided by the cloud service suppliers" [7].

\subsubsection{Software as a Service (SaaS):}

Most commonly used service model of cloud computing. In this computing model Applications are managed by the provider and provided to the customers over network (internet). Most of the web applications are provided throw SaaS. SaaS is shown on the top layer in figure 2.

\subsubsection{Platform as a Service (PaaS):}

PaaS is a subcategory of the IaaS and provide a platform to customers (developers) to create their own applications. It has many other benefits as well. For example if you work in enterprise then you can work from anywhere as team.

\section{INCREASING ROLE AND IMPACTS ON BUSINESS:}

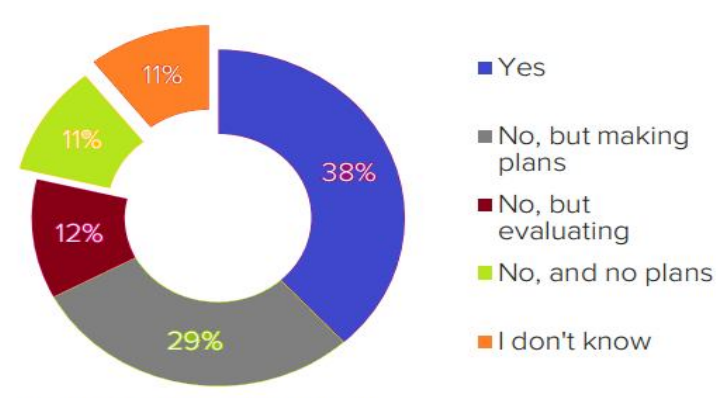

Source: Vanson Bourne "The impacts of cloud on business"

Figure 3 Impacts of cloud on business: Vanson Bourne, 2012

Now a day's cloud computing is spreading all over the world because of advantages over traditional methods. Cloud technology has become the slogan in the business now a days. Although, Cloud computing is not completely newer idea but in this modern era, cloud computing is become essential due to excessive use of internet, mobiles, demand of more bandwidth from the end users. The end user can be a simple consumer, may be a small business or an enterprise. Main focus of small level businesses towards usage of cloud technology and these small enterprises taking advantages of this technology [1].

Cloud technology (computing) has ability to alternate how corporations maintain IT and think economically in hardware 
and software point of view. Cloud computing assured that it brings a group of business persons who can begin their businesses from no initial cost on information technology setup [8].

In these days cloud technology is gaining popularity rapidly and become famous as business model. In which resources are provided to the end-users when they demand these computing resources. The distinctive values of cloud computing produces fresh openings to line up information technology and industry goals [7].

\subsection{Increasing role in businesses}

In March 2012, market research company Vanson Bourne conduct a survey, where they interviewed 460 senior financial decision-makers of those companies which have more than 500 employees from different countries. When they ask question: Are organizations adopting cloud computing? "A total of $38 \%$ of those we spoke says their company has already implement cloud solution and 29\% says they are making plans to implement" [9]. As shown in the figure 3.

\subsection{Impacts on businesses:}

In their survey to different senior financial decision-makers. They concluded that companies who implement cloud technology has received better results in their business.

Some of the results are following companies who embraced cloud computing in their businesses a $20.66 \%$ average improvement in time to market, their results for process efficiency increased are $18.80 \%$ average and $15.07 \%$ reduced in money on IT related expenses. They mentioned in their results, combined benefits to the company growth is $19.63 \%$ [9]. As shown in figure 4.

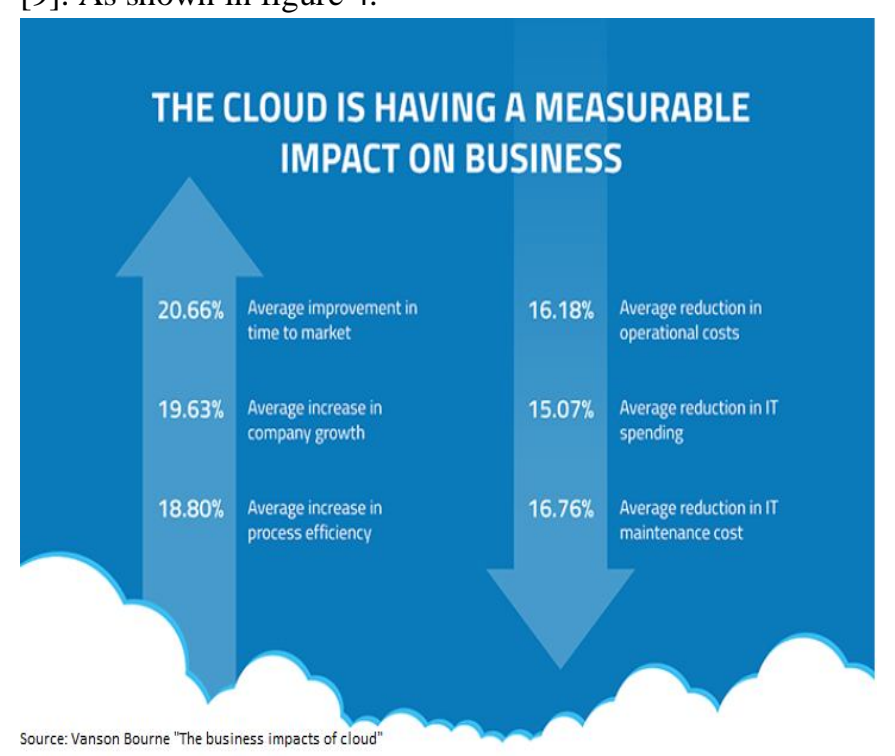

Figure 4the business impacts on cloud. Source: Vanson Bourne, 2012.

\subsection{Benefits of cloud in business:}

Software as a Service (SaaS) reduces software acquisition risk of an organization enabling it to meet business goals quickly. For example, Information Technology (IT) department of an organization would be able to utilize Software as a Service (SaaS) for meeting organization's business goals quickly without worrying about software update burden and resources maintenance burden. Software as a Service(SaaS) has potential to enable information technology department to work as computing services provider helping organization to meet business goals without investing in software acquisition which is very attractive benefit of cloud computing [10].

With the increasing role of cloud computing in business it has many benefits as well.

\subsubsection{Higher Performance:}

Worker can do their work from anywhere and anytime throw any resource like smart phone, tablets etc. That increases the performance of business.

\subsubsection{Cost effectiveness:}

Corporations don't need to buy any type of apparatus and no need to spend lot of money on data centers. That saves lot of money.

\subsubsection{Flexibility in capacity:}

Depending on the circumstances we can increase or decrease in capacity. For example, a sales is widely popular, capacity can be added to avoid any accident.

\subsubsection{Higher availability:}

Employees can work although they are in the field or visiting customers in their offices or homes. They have access of system to perform their duties.

\subsubsection{Increase Collaboration:}

Instead of work separately, employees can work together on same projects from different geographical place.

\subsubsection{Flexibility in cost:}

Cost of cloud is much flexible than traditional ways. Companies only pay for those resources that they needed. No need to pay for those resources that you don't need at current time.

\subsubsection{4/7 Availability:}

Many cloud providers are very reliable and customer can use their services anytime, you need to have only internet connection.

\subsubsection{Latest software's:}

In SaaS, latest version or updates of Apps and software's that required are offered to all customers when they released. 


\subsubsection{More can get with less:}

In cloud technology, corporations can eliminate their datacenters are limit them in small size. IT staff is also reduced. Less number of servers required

\section{CHALLENGES TO CLOUD FOR COMPLETELY PENETRATE IN BUSINESS:}

Following are the challenges that cloud is facing to completely penetrate in businesses.

- Lack of resources/Expertise

- Security

- Managing cloud spends

- Compliance

- Governance/Control

- Managing multiple cloud services

- Complexity in building private cloud

- Performance

The conclusions shown that comparative benefit, top administration backing, size of the organization, competitive burden, and dealing partner burden characteristics have a major influence on the implementation of cloud technology [11].

\subsection{Overall decline in challenges:}

Challenges exit in adoption of cloud computing technology, but with all these challenges, there are lot of openings in the field of research into numerous sides of the cloud technology who demonstrate that these challenges can be eliminated. Heterogeneous data centric safety is one of the solutions for access control of data. A records safety architecture includes of verification, encrypt the record and reliability of data, retrieval of data, end user security has to be intended to increase security of data on cloud computing. To guarantee confidentiality and security another service should be used that is "data protection service" [12].

During the year 2017, challenges in cloud computing are decreased exponentially except control and governance shown in figure (5), that remain same as in 2016. In year 2017Lack of resources/expertise, managing cloud spends, and security is decreased but they are still top challenges.

When we discuss these challenges individually, Lack of resources/expertise were on 32\% in 2016 and in 2017 they decreased to $25 \%$. Worries about security decreased to $25 \%$ from 29\%. Managing spend also decreased somehow from $26 \%$ to $25 \%$ [13]. As shown in figure 5.

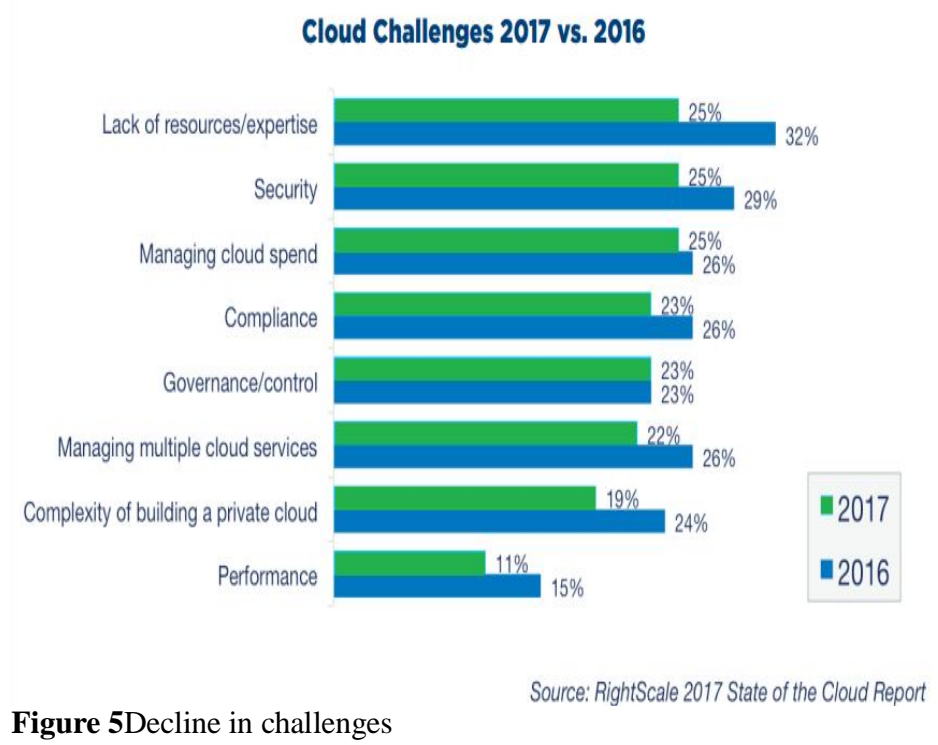

\subsection{Decline in challenges with Cloud Maturity}

Report show that The overall challenges decrease with the cloud maturity. For the cloud beginners challenges are too high but as companies matured in cloud usage, their challenges reduced very quickly. Figure (6) gives a brief comparison between Cloud beginners, explorers and cloud focusedusers.

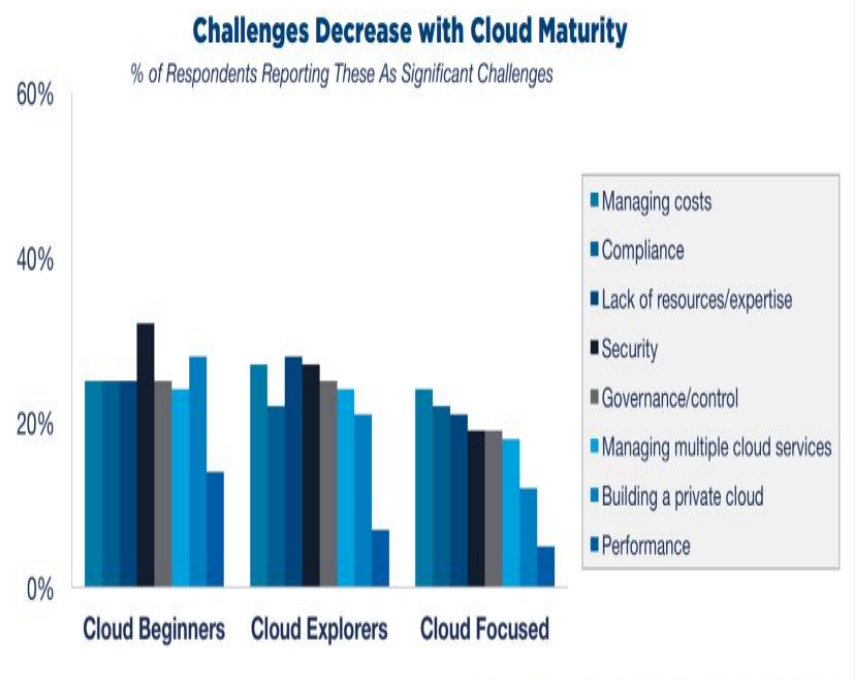

Source: RightScale 2017 State of the Cloud Report

Figure 6Challenges Decrease with Cloud maturity

\section{CONCLUSIONS:}

The present article represents a supplementary argument in favor of cloud computing roles in business. This paper conclude that, the Increasing role of cloud computing has many positive impacts on business in many areas like efficiency, time to market, company growth, IT and maintenance cost etc. And decrease in Challenges for cloud in business with comparison of two years 2016-2017. That proves that challenges are declining very quickly. One most important thing from business point of view is challenges are decreasing with cloud 
maturity. As the company matured in cloud usage they face less difficulty as compared to cloud beginners.

\section{AUTHORS CONTRIBUTION}

All authors had approved the final version. Corresponding Author is Musaddiq Azeem.

\section{REFERENCES}

[1] Etro, F, The economic impact of cloud computing on business creation, employment and output in Europe. Review of Business and Economics, vol. 54, no. 2, pp. 179$208,2009$.

[2] Leimeister, S. and Böhm, M. et al,The business perspective of cloud computing: actors, roles and value networks, 2010.

[3] Avram, M.-G, Advantages and challenges of adopting cloud computing from an enterprise perspective. Procedia Technology, vol. 12, pp. 529-534, 2014.

[4] Shahzad, F,State-of-the-art survey on cloud computing security challenges, approaches and solutions. Procedia Computer Science, vol. 37, pp. 357-362, 2014.

[5] Weiss, A,Computing in the Clouds. networker, vol. 11 no. 4. pp. 16-25, 2007. New York: ACM, 10, 1327512.1327513.

[6] Zhang, Q. and Cheng, L.et al,Cloud computing: state-ofthe-art and research challenges. J Internet Serv and Appl vol. 1, pp. 7-18,2010.

[7] Nandgaonkar, S. V. and Raut, A,A comprehensive study on cloud computing. International Journal of Computer Science and Mobile Computing, vol. 3, no. 4, pp. 733738.2014.

[8] Sreedharan, S. S, Security and privacy issues of cloud computing; solutions and secure framework. IOSR Journal of Computer Engineering, vol. 10, no. 4, pp. 33-37, 2013.

[9] Bourne's, V,Business Impact of the Cloud. City, 2012.

[10] Carraro, G. and Chong, F,Software as a service (SaaS): An enterprise perspective. MSDN Solution Architecture Center, 2006.

[11] Low, C. and Chen, $Y$ et al,Understanding the determinants of cloud computing adoption. Industrial management \& data systems. 2011.

[12] Rao, R. V. and Selvamani, K,Data security challenges and its solutions in cloud computing. Procedia Computer Science, vol. 48, pp. 204-209, 2015.

[13] Trends, C. C,State of the Cloud Survey, 2018. URL: https://www. rightscale. com/blog/cloud-industryinsights/cloud-computing-trends-2018-statecloud-survey (дата обращения: 15.05. 2018). 